\title{
Article
}

\section{Domiciliary Care: The Formal and Informal Labour Process}

Bolton, Sharon. C and Wibberley, Gemma

Available at http://clok.uclan.ac.uk/10932/

Bolton, Sharon. C and Wibberley, Gemma ORCID: 0000-0002-7827-8227

(2014) Domiciliary Care: The Formal and Informal Labour Process. Sociology, 48 (4). pp. 682-697.

It is advisable to refer to the publisher's version if you intend to cite from the work. http://dx.doi.org/10.1177/0038038513500098

For more information about UCLan's research in this area go to

http://www.uclan.ac.uk/researchgroups/ and search for <name of research Group>.

For information about Research generally at UCLan please go to http://www.uclan.ac.uk/research/

All outputs in CLoK are protected by Intellectual Property Rights law, including Copyright law. Copyright, IPR and Moral Rights for the works on this site are retained by the individual authors and/or other copyright owners. Terms and conditions for use of this material are defined in the policies page.

\section{CLoK}

Central Lancashire online Knowledge www.clok.uclan.ac.uk

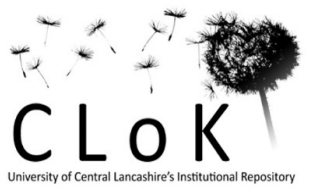




\title{
Domiciliary care: the formal and informal labour process
}

Key words: care-work, domiciliary carer, labour process theory, marketization

\begin{abstract}
Domiciliary carers are paid care workers who travel to the homes of older people to assist with personal routines. Increasingly, over the past twenty years, the delivery of domiciliary care has been organised according to market principles and portrayed as the ideal type of formal care; offering cost savings to local authorities and independence for older people. Crucially, the work of the former 'home help' is transformed as domiciliary carers are now subject to the imperative of private, competitive accumulation which necessitates a constant search for increases in labour productivity. Drawing on qualitative data from domiciliary carers, managers and stakeholders, this article highlights the commodification of caring labour and reveals the constraints, contradictions and challenges of paid care work. Labour Process Theory offers a means of understanding the political economy of care work and important distinctions in terms of the formal and informal domiciliary care labour process.
\end{abstract}

\section{Authors}

Bolton, S.C. and Wibberley, G.

Stirling University, sharon.bolton@stir.ac.uk

\section{Gemma Wibberley}

Research Associate

iROWE (Institute for Research into Organisations, Work and Employment)

Gr 263

Greenbank Building

Lancashire Business School

University of Central Lancashire (UCLAN)

Preston

PR1 2HE

01772894674 (ext 4674)

gwibberley@uclan.ac.uk

\section{Introduction}

Domiciliary carers are paid care workers who travel to the homes of older people and assist them with their personal routines. Increasingly, over the past twenty years, the delivery of 
domiciliary care has been organised according to market principles and portrayed as the ideal type of formal care; offering cost savings to local authorities and independence for older people. Consequently, the domiciliary carer's role has expanded from offering domestic service to offering personal and health care. In addition, they face unprecedented challenges in the way they must move from place to place, mostly working alone, dealing with mentally and physically fragile clients. Crucially, the labour of the former public sector 'home help' is transformed into a commodity form as domiciliary carers are now subject to the imperative of private, competitive accumulation which necessitates a constant search for increases in labour productivity; most often represented by intensified work regimes, changed divisions of labour and different forms of control.

The analysis presented in this article highlights the commodification of caring labour and reveals the constraints, contradictions and challenges of paid care work. Labour Process Theory (LPT) is proposed as a theoretical vehicle that offers a means of understanding the political economy of care work and important distinctions in terms of the formal and informal domiciliary care labour process. LPT understands caring labour as a form of human activity that takes on a particular character under capitalism. It connects what might be classified as intimate activity within a home-work space to the broader political economy. Thus, LPT considers the inherent tensions of care work in the context of the push to marketise care services, the introduction of new managerial control regimes that aim to capture the variability of labour power (the indeterminacy of labour), and employers' reliance on discretionary effort (Thompson and Smith, 2009).

Drawing on rich qualitative data from interviews with, and shadowing of, domiciliary carers, managers and stakeholders, this article highlights how LPT places useful analytical and context-specific boundaries around existing knowledge of the domiciliary care labour process. In this way an understanding is offered of the determining factors that create the conditions for how domiciliary care is delivered. Importantly, for the analysis presented here, LPT departs from a fixed workplace context to the homes of the elderly as unique work spaces. Within this context a delineation of labour power that is captured in the prescribed labour process and that which is exercised outwith the formal prescription is important; in what might usefully be described as the formal and informal labour process. The formal labour process highlights specific, and often contradictory, aspects of control mechanisms that detail tasks to be completed and, most importantly, emphasises the person being cared for as a site of labour; whilst the informal labour process is activity which is excluded from 
the prescribed labour process but, nevertheless, serves to support it (though, of course, it may also undermine care giving activity).

The LPT framework of the formal and informal labour process reveals the dynamics of the market-driven nature of managerial attempts to streamline and standardise care work in response to the indeterminacy of labour, whilst emphasising that care remains essentially a social relation. It is most frequently the exertions of the domiciliaries that ensures seamless delivery of profit-centred care whilst maintaining human connection. A paradox emerges that whilst new control regimes seek to standardise and rationalise care giving activity, employers are reliant on workers' extra effort. The care labour process could not operate effectively without the very indeterminacy capital attempts to squeeze out. An examination of the political economy of care work and the formal and informal domiciliary labour process captures the essential character of domiciliary carers' labour power and engages in a sociology of work that renders visible that which capital relies upon but takes for granted.

\section{Political economy and the domiciliary care labour process}

Domiciliary care is a labour process, like any other, placed within temporal and spatial boundaries and connected to the broader political economy (Bolton, 2010; Thompson and Smith, 2009). Labour process theory (LPT) offers the analytical tools that delineate how the labour process of a domiciliary carer is shaped by economic and social factors, how their bought and paid for labour time is focused on care as a tightly defined, task-based commodity and how this commodification of care entirely neglects that any labour process does not exist in a human vacuum but is supported (or undermined) by social relations. The factors that shape and determine the domiciliary carers' labour process serve to define what is recognised as the formal labour process and what is squeezed out but is, nevertheless, essential to the task in hand - the informal labour process. Only by examining the political economy of domiciliary care and the formal and informal labour process can it be understood what is entailed and why elements of their work are unrecognised and under-valued. A labour process lens reveals how organisations (and clients) become reliant on the discretionary effort of domiciliary carers, and the way management control regimes fail to recognise the nature of the labour power they try so hard to capture and control.

LPT has travelled on various 'waves' but its central concerns remain; that is, the logic of capital impels organisations to continually reinvent the control imperative, the potential for the intensification and degradation of work within new forms of work organisation, and, ultimately, the extraction and exploitation of labour power and its transformation into a 
commodity form (Edwards, 2010; Thompson and Newsome, 2004; Thompson and Smith, 2009). The theory shows how the marketisation of welfare services means that even when labour processes are not directly profit driven they are controlled as though they are (Bolton, 2005; Carter and Stevenson, 2012). But much more than this, it explores how labour is not just an instrumental activity but a social one as it involves and sustains relations with others, hence, the labour process is mediated through human action (Sayer, 2007).

Importantly, the careful delineation of the labour process as the point of transformation of the capacity to labour into actual labour effort supports the analytical distinctions of the formal and informal labour process. Here these concepts are integrated into an analytical device that captures the dynamics of a political economy of care work. In applying this framework to domiciliary care it captures the processes of extraction and exploitation of the ability to offer care in very different settings and domiciliary carers' reactions to these attempts. It overcomes the problems of connectivity by highlighting the different aspects of domiciliary care and the demands that are made of paid-carers. LPT allows an incorporation of a wide field of analysis as it recognises that domiciliary care is a mix of different forms of labour that involves hands, hearts and minds. Thinking in terms of caring for older people as a labour process also reveals the home as a work space and the person receiving care as an object to be produced - soiled, hungry, anxious people transformed into clean, replete, calm people (Lee-Treweek, 1997; Toynbee, 1997; Wolkowitz, 2002). LPT also emphasises that what is sold in exchange for a wage is the capacity to labour, in the case of the domiciliary worker it is also a capacity to care, which may or may not be invested with concern, empathy and kindness (Bolton, 2010). In this way a picture is presented of the richness of domiciliary care work whilst at all times keeping an eye on the workings of a marketised system that continually serves to squeeze out the human exchange involved.

Care work, and its association with the domestic sphere, has long been at the heart of attempts to define and value it as a form of labour - in or out of paid employment. Buebeck (2002), for example, insists that care is a form of labour as it demands an individual's input, 'time and energy.' However, he also states that care work is very different from other forms of labour as it requires that the worker focuses on 'the other' and their needs. Building on the recognition of caring activity as a very particular form of 'work', care-work debates are concerned with defining the level of caring invested in such work and how to gain recognition for those who deliver it. Care-work is typically recognised as being undervalued due to its links with informal care (Stacey, 2011), the perceived lack of skill (Toynbee, 2007), 
the 'dirty work' (Bolton, 2005b) and 'bodywork' (Wolkowitz, 2010) involved, and the gender and status of the worker (Ehrenreich and Hochschild, 2002). For those located within the private sphere, the invisibility of their labour further compounds this devaluation.

In terms of caring for older people, increasing the visibility and perceived value of such work offers different challenges as the status of the carers and those being cared for are inextricably intertwined (Bittman et al., 1999). Even paid care work that is clearly part of a profit-making machine remains what Polly Toynbee, reflecting on her time working as a care assistant in a private residential home for older people, refers to as 'unseen, unmentionable labour' (Toynbee, 2007: 239). Nevertheless, globally there is a growing demand for paid carers to address what has become known as the 'care deficit' (Ehrenreich and Hochschild, 2002). An army of care-workers now carry out the dirty work of dealing with leaky bodies and unsettled minds. The private care agencies and homes aim to accumulate capital and, thus, caring labour becomes the object of intricate control mechanisms (Diamond, 1992; Lopez, 2006). This brings a different perspective; displaying the exploitation of both carers and clients that lies at the heart of the care-cash nexus.

\section{The evolution of domiciliary care}

The NHS and Community Care Act 1990 emphasised a reduction in residential care for older people and an increase in the provision of home care. The weekly domestic support of the home help transformed into daily care (often thrice daily) provided by a domiciliary carer. The newly defined role may include activities such as administering medication, bathing, and toileting. This role stretch is, in part, to do with the changing needs of the clients, as the majority of those receiving Social Services funding are likely to have severe physical and/ or mental health problems. However, it is also argued that it is a means of cutting costs as domiciliary carers are a cheaper resource than district nurses (Twigg, 2000). Like other care workers, the majority of domiciliary carers are women, who often have caring responsibilities themselves and are likely to be middle-aged and working class. Migrants and members of the black and minority ethnic communities are overrepresented in the domiciliary care workforce (Timonen and Doyle 2007).

Prior to the 1990s, home care was mainly provided by people working for local authorities. However, in line with the marketisation of public services, local authorities have now outsourced the majority of domiciliary care to the private sector ${ }^{\mathrm{i}}$ in the search for cost savings and efficiency gains (Rubery and Urwin, 2011). The outsourcing of domiciliary care services claims to have reduced the overheads involved in directly employing care workers 
(Young, 1999). However, the largest cost savings is from private care providers forced to compete for Social Services contracts. Competitive pressures are linked to the sector's low pay, long (and unsociable) hours and poor working conditions (Rubery and Urwin, 2011). Private domiciliary care providers argue that it is Social Services' low rates which prevent organisations from providing guaranteed hours or jobs, or paying higher rates of pay and benefits (Young, 1999). However, critics argue that large 'for profit' care organisations are the key beneficiaries of privatisation, changing the prime goal of care giving away from fulfilling the needs of the client towards market competitiveness (Carey, 2006).

Structurally, the problem with domiciliary care, and other care occupations, is that it is difficult to increase profitability through any other means than standardising and intensifying the pace of work for the care-givers. Unlike other industries, there is little scope for automation, and increasing productivity is limited without reducing the quality of care (Baumol, 1993; Cohen, 2011). As a result it is the domiciliary carer who bears the downward pressures of fierce competition, with average wages barely above National Minimum Wage (NMW) and various 'flexible' work arrangements, such as zero hour contracts, being the norm (Rubery and Urwin, 2011). The economic devaluation of domiciliary carers is matched by the low status of the occupation (Aronson and Neysmith, 2006; Stacey, 2011). And yet, paradoxically, the domiciliary carer's role continues to expand. Tasks can range from manoeuvring a client in and out of bed, washing, dressing, toileting, meal preparation and feeding, health care tasks and domestic chores (Sinclair et al, 2000; Cooper, 2004). The particular activities are determined by the client's care plan which dictates the activities of domiciliary carers. However, the literature suggests that necessary tasks are not acknowledged in the care plan such as information provision (Cooper, 2004), and the continual emotion work involved in delivering caring tasks (Brown and Korcynski, 2010; Stacey, 2011). Nor do care plans represent the hard physical labour involved in the dirtywork of body-work (Twigg, 2000; Stacey, 2011).

The domiciliary carer most often operates alone, often making autonomous decisions regarding a client's care. Yet, as with other occupations, and distinctively from informal and direct care, their work is determined by several factors that all feed into care organisations' need to account for the cost of billable time through the use of monitoring, rotas and care plans (Davies and Drake, 2007). Little wonder that the care plan is minimalist in nature, focusing on routine physical tasks. The number of care visits and their length per client have been gradually reduced via rotas, a timetabling control system, that dictates where a domiciliary carer must be, when, and for how long (McClimont and Grove, 2004). In the 
private sector these rotas offer no recognition of the spatially segregated nature of caring for people in their own homes. This is because travelling between clients is not paid for by Social Services to private domiciliary care organisations and, in turn, is not paid by the organisations to the domiciliary (Rubery and Urwin, 2011). Travel is therefore not registered as working time, and domiciliary carers are expected to do significantly more work in less time (Aronson and Neysmith, 2006; Cuban, 2013). Hence, without sufficient time to provide all the care required, domiciliary carers are often faced with the problem of having to decide what care can actually be provided to which client. Thus, many will perform care tasks outside of their working hours (Sinclair et al, 2000; Cuban, 2013); or undertake unauthorised tasks, especially household chores and errands (Sinclair et al, 2000; Stacey, 2011); or not follow management guidelines when they feel that they conflict with caring needs (Brown and Korczynski, 2010; Stacey, 2011).

Despite the complexity, autonomy, and gruelling physical and emotional work involved in domiciliary care, it is not a role that is either highly regarded, thus attracting status, or highly rewarded, thus attracting decent pay and conditions. On paper at least, domiciliary care is reduced to a tick list of basic physical tasks to be completed in a set period of time; the required physical, mental and emotional stamina and skill that is needed to care for clients is entirely neglected.

\section{Methodology}

Qualitative data has been collected through the use of interviews and shadowing with 74 people from across the domiciliary care sector in England. 47 respondents engaged in semistructured interviews, including domiciliary carers, domiciliary care managers and stakeholders. All 19 domiciliary carers interviewed were female, and were split by employer: ten local authority, eight private sector and one directly employed by clients. Of the 14 managers, four were male, and two worked for local authorities. The stakeholders interviewed included consultants on social care, people working for a care employer's association, and trade unionists, service providers and users. Interviews were designed to elicit information about terms and conditions of domiciliary carers' employment, the labour process of domiciliary care, and the context of the sector. Shadowing was utilised to reveal the differences between espoused and actual practice (McDonald 2005). Eleven domiciliary carers, ten office staff and five managers were shadowed as they went about their day-to-day work; around 60 hours in total. All but two of these participants were a different cohort to the interviewees and only two (both mangers) were male. This was split across two private DC 
organisations (it was not possible to access any local authority providers). Both organisations are located in the North of England. Organisation A is a large organisation in a rural location, whilst Organisation B is located in a more urban setting and is a small organisation in which the owners are also the managers and deliverers of care. Access was granted to accompany staff as they went on visits to clients, attended meetings, and undertook training. All participants have been anonymised.

Sample data drawn from engagement with the domiciliary care community is presented within the analytical framework informed by labour process theory in order to exemplify both the complexity and variety of their work and, at the same time, to help to account for its invisibility.

\section{The political economy of domiciliary care}

To understand the domiciliary carers' labour process, an exploration of the factors that shape it is worthwhile. These factors show that domiciliary care work is connected to the political economy through a web of intricate structural relationships and institutionalised methods of working, i.e., the changing political landscape for public services, and division of labour in health-care. As mentioned in the review above, a key constraint is the marketisation of services and the squeeze on funding for caring services, particularly for private domiciliary care organisations. However, the domiciliary carers' labour process is also determined by the influence of stakeholders, the physically and mentally fragile nature of the clients, the spatial and temporal obstacles faced on a daily basis and the control mechanisms of the organisations providing care to older people in the shape of the rota.

Beginning with stakeholders, respondents describe Social Services as the major customer for most privately run domiciliary care organisations. It is also Social Services who dictate which clients receive funded care, the levels of care, and the provider. Once the care service is in place, Social Services remain responsible for reviewing the care of the clients they fund, and care organisations require consent before adopting any proposed changes to the care of the client. This obvious disconnection between conception and execution can lead to tensions between Social Services and care organisations, and difficulties in adapting client care:

'We find it hard to get more time for people...You've gotta go to the supervisor....and then they've gotta go and get through to the social worker and they've gotta to pay a 
visit and then they've gotta get back to you, and then sometimes it's too late.' (Alice, Domiciliary Carer)

The NHS has a dual role within domiciliary care. Most commonly it is seen as a 'colleague', which provides essential support to domiciliary carers in caring for clients, and a wide range of health care workers are mentioned. Nevertheless, as with Social Services, respondents report a power imbalance between health care and domiciliary care, and this is resented by the latter. Many in domiciliary care feel that health care tasks are being delegated to them due to financial constraints in the NHS, and believe that this is not always beneficial. Respondents also argue that client needs have increased because of reductions in residential care and tightened eligibility criteria for state funding, resulting in clients who have high levels of physical and mental needs receiving care in their own homes. A major factor, therefore, shaping the domiciliary carer's labour process is that it takes place within a client's own home, where ability to control workspace is limited. Clients' homes can be challenging as a workplace as they vary in their layout, cleanliness, atmosphere, inhabitants, equipment and space. As observation of Amy and Lucy (domiciliary carers) demonstrates:

A hoist sling is put on a client, Michael, by Amy and Lucy and attached to the hoist. Michael is lifted in the hoist from an armchair, placed into a wheelchair, and wheeled into the bedroom. He doesn't communicate much in response. They reattach him to the hoist, which is moveable and the domiciliary carers have to physically push the hoist with Michael attached. They comment on the difficulties of remembering which sling and hoist work in which ways as the clients do not all have the same equipment. Amy and Lucy move the hoist over the bed, lower Michael's trousers and underwear, and clean and cream his bottom whilst he is above the bed. Michael is then lowered into a hospital style bed, the sling is detached from the hoist and removed. They remove his clothes and put on his pyjamas. A relative comes in to the bedroom, advice from a health-care worker is discussed and they then leave. The domiciliary carers change the catheter, a night-bag is attached to the day-bag, taps have to be opened and the bag attached to the bed. The domiciliary carers make the bed and ensure Michael is in a suitable position for the night.

This snapshot highlights the fragility of clients, the care they require and the technical complexity and challenges involved. It also demonstrates that domiciliary carers have to deal 
with relatives in a way that other care workers may not due to the lack of temporal or spatial boundaries between the work and domestic space (Milligan and Wiles, 2010).

Domiciliary carers generally work alone, sometimes doubling up with another if the visit is particularly challenging. Managers are typically located in the base office, or out in the community visiting other clients, and respondents believe that the lack of on-site management requires domiciliary carers to be more autonomous and responsible:

'It's so different from residential...[you] have the supervisor in the [residential] home, if there's a problem you can just, get it instantly fixed... but in home care, its phone up the coordinator... and act on your own initiative...If you go and knock on a door, somebody might not be in...or ...died.' (Susan, Domiciliary Carer)

Working in a range of different work spaces throughout the day means that domiciliary carers must continually be on the move between clients' homes resulting in the introduction of ever more complex control mechanisms to ensure efficiency levels are maintained. The 'Rota', for example, is a list of all the clients that a domiciliary carer must visit each shift, along with the times that these visits must take place, and the allocated duration of the visit. The rota in private domiciliary care organisations rarely includes time for travelling between clients' homes. Often domiciliary carers are scheduled to arrive at the next client at the same time as leaving their previous client; a logistical nightmare for managers, domiciliary carers, and clients. Far from being merely an administrative tool, the rota represents the political economy of domiciliary care work in the way its organisation intensifies the labour process due to funding systems that only pay for tasks completed and not travel time between spatially segregated work spaces, nor does it allow for the unpredictable demands made by clients. However, the rota may shape the organisation of care work but it is the care plan that defines the actual domiciliary care labour process.

\section{The formal labour process}

Funding systems, workspace, stigma, and the rota set temporal, spatial, political, social and economic boundaries around the labour process of domiciliary carers. However, it is the care plan that is the central means of transforming the capacity to labour into productive labour. The care plan is said to represent the work of a domiciliary carer but it neither recognises the complexities of the work involved nor its multi-layered nature. It is entirely based on direct task-related activity without any recognition of what it is that supports the successful 
completion of such activity. Care becomes a tradable commodity and domiciliary carers have to continually reconcile the tensions inherent in a care plan that offers no time to care.

The care plan lists the tasks to be performed during a visit (see figure one for an example). Domiciliary carers are expected to read it at the start of each visit and follow its instructions. Respondents frequently state that it is forbidden to perform tasks that are not on the client's care plan and, furthermore, there are strict guidelines on prohibited activities such as changing light bulbs. Thus the care plan is a bureaucratic form of controlling staff. For example, some managers create scripts for caring in an attempt to further standardise and routinize labour practices within a heterogeneous workforce. Care plans are pre-prepared in conjunction with the domiciliary care organisation and the client, and sometimes relatives and, if different, the funder. The care plan is, therefore, not a benign document but reflects dominant priorities and interests which are never focused on the domiciliary carer and, paradoxically, rarely on the client (Steinberg, 1999). It is designed so that in theory any domiciliary carer is able to care for any client, and perform the same tasks, regardless of whether they have worked with that client before:

'[The care plan for each client says]... 'first daily call, $2^{\text {nd }}$ daily call, $3^{\text {rd }}$ daily call $\ldots$ so in theory you could turn up completely blind to a new person's house and know exactly what you had to do, which was good because...sometimes they're [the client] not compos mentis enough to tell you' (Alex, domiciliary carer)

Figure 1 Here

Full care plans also offer information about the client such as: physical or mental health problems; impairments; and medication taken. Information will also be provided about their house and other household members. Nevertheless, the care plan does not always represent a complete picture of the domiciliary carers' labour process. Looking at the labour process in more detail, when participants are initially asked about their tasks they typically give a very simplistic description and present their work as straight-forward and routine:

'Evening shift it's undressing people, changing their [incontinence] pads, and putting them to bed...whereas in the morning it's getting them up and making them nice and fresh, ready for the day...Dinner slots... all you're doing is putting a microwave meal 
in... switching it on, setting a table, making a cuppa tea, plating it in up, and then off you go... pots'll be there at tea-time, and the tea-time (domiciliary carer) comes in...to tidy up, that's if (client) can't do it themselves.' (Jen, domiciliary carer)

However, what becomes clear is that Jen, and others, have normalised the intensity of their work schedule and the complexities involved so that they summarise what they do and the work involved in 'getting them up and making them nice and fresh' is taken-for-granted. In fact, domiciliary carers' work has become more challenging due to the increasing range of health care tasks required, such as changing dressings and offering physiotherapy which have been almost casually added into domiciliary carers' daily tasks without due reward or recognition. As Beverly (Manager) reflects:

'[Domiciliary carers] have had their duties increased, they now have to administer medication...deal with catheters, stomas ${ }^{\mathrm{ii}}$... because the district nurses haven't got time.'

Respondents are often concerned that the demands placed on domiciliary carers undertaking some of these health care tasks are unreasonable given their position in the health care division of labour; as Nicola (Domiciliary carer) expresses:

'[A] (Colleague)'s actually learnt to PEG feed ${ }^{\mathrm{iii}}$ somebody... I'm not a nurse, that's a nurse's job ...I think that's a very big responsibility...I think it's wrong.'

And yet domiciliary carers demonstrate high levels of knowledge regarding health conditions. For instance, when dealing with catheter bags they need to know which is the night or day bag, and how the two are attached differently, and how to do this correctly, as mistakes can lead to leakages or infections. This delegation of health care tasks has been widely noted, with a reduction in nurses leading to increasing demands on domiciliary carers (Aronson and Neysmith, 2006; Milligan and Wiles, 2010; Stacey, 2011).

The domiciliary carer's labour process has intensified in terms of these additional tasks but also in terms of pace of work, with staff observing that there is often insufficient time to undertake all the activities required. As domiciliary carer, Maria, notes 'It's not physically possible' and Nicola, her colleague, describes: 
'I mean you have half an hour, you go into in a job, you're supposed to read the book, find out what's been happening...to that person...by the time you've got through the door, you've said hello to the person, you've done that, 10 minutes is at least gone... and then you're supposed to...shower them, dress em, feed em, medication, make the bed, well... with all the will in the world'

Domiciliary carers are continually finding ways of saving time during visits: by working quickly, developing efficiencies, and prioritising tasks. Nevertheless, the care plan demands are too great to be contained within the allocated time as there is no acknowledgement of unpredictability or the human connection that supports the labour process. This frustrates many respondents, such as Trudy (Manager):

Interviewer: "You were saying about communicating with the clients, do (domiciliary carers) have much time to?...

Trudy: (sighs)...We did...but we're governed by the amount of time commissioned... so if the commissioners, commission...45 minutes for personal care in the morning...it takes 45 minutes...obviously (domiciliary carers are) conversing as they're doing jobs...but there isn't the time then to sit and have 10 minutes chat...and that's what (clients) need."

\section{The informal labour process}

The care plan attempts to create a standardised, task-based model of billable time but, in reality, it is unlikely that the intimate nature of caring tasks, the variable and complex demands of the client, and the domestic setting would support such a simplified approach or the separation of physical and emotional labour (Aronson and Neysmith, 2006; Cohen, 2011; Nare, 2011). In effect, the care plan does not provide a complete picture of the domiciliary carer's labour process and its complexity. For example, the care plan suggests that clients' needs are stable and routine. However, people are unpredictable, most especially frail and anxious people. Domiciliary carer Sarah explains how it is not unusual to find clients have fallen and that she needs to call an ambulance. Whilst domiciliary carer Freda describes how her routine is often disrupted and care-plan tasks need to be repeated: “As I was leaving, [the client] said to me 'oh I really need to go to the toilet, I think I've had an accident'...you stay...help her to get...cleaned up and re-dressed." And, of course, it is not merely a matter of leaky bodies, people are 'needy beings' (Sayer, 2007), as Marie (domiciliary carer) vividly 
portrays in her description of working with a client with Obsessive Compulsive Disorder (OCD):

'I had half an hour to get... (client's) meal out, sorted to her specification, and what she wants to eat. It took her 10 minutes to decide...I was still very patient, could I work the bloody microwave, could I heck... Then she said 'Stop...you are not warming my plate'. I said 'It's too soon...I'll do it just before the end, and then your plate's not too hot'...And I got her plate...warm...and then I...put her empty microwavable container...in the bin, well that was it....She flew 'That goes in the sink, stop, stop, stop.'

The care plan entirely neglects the negotiation and communication skills Marie requires to encourage the client to have a meal within time constraints and the emotion work involved in managing Marie's own feelings of frustration along with the client's anxiety. It offers a disembodied form of care-work that does not include recognition of the way domiciliary carers interact with clients, their relatives and other workers that are present in the house. For example, sitting and talking with clients rarely appears on the care plan. Domiciliary carers frequently mention that conversation and engagement with clients only happens if they have an opportunity to fit it in at the end of their visit, or they use their own (unpaid) time to 'have a chat', such as Izabelle and Alice (domiciliary carers):

Izabelle: "[Clients] like to have a drink with you and talk to you as well... Interviewer: Do you find you have a little bit of time to do that...?...

Alice : Well we make it don't we a lot of the times?...'We're off this afternoon, but no we'll hang on a bit'."

Some tasks previously formed part of the domiciliary carer's job. However, typically they are officially being moved out of the role, through the lack of social services funding for that activity (McClimont and Grove, 2004). For instance, due to domiciliary care taking place in a client's own home, people often request help with domestic tasks. However, unless the client is self-funding and has paid for these tasks they are generally not supposed to be performed. This places the domiciliary carer in the difficult position of choosing between fulfilling clients' needs or following company guidelines:

"(A client) had a coal fire and her coal was kept outside, so me and my friend... used to always go and fill the coal up for her, but a lot of the other (domiciliary carers) 
wouldn't do it, because they said 'We're not insured and if we go outside and slip it's a job that isn't on the care plan'.” (Roxanne, domiciliary carer)

Other off-plan tasks are created via managers', clients' and the domiciliary carers themselves unwritten expectations. Managers may expect domiciliary carers to informally train colleagues and to unofficially constantly review clients. Clients may have unrealistic or outdated expectations of the role of the domiciliary carer (Cooper, 2004), such as the continuation of domestic labour from the era of home helps. Alternatively clients request tasks that are typically within the remit of health care professionals, for instance health care advice.

The domiciliary carers themselves report sometimes choosing to undertake extra work that was not on the care plan, often resulting in unpaid overtime. Many comment on doing 'little tasks' for clients that were against company rules, such as putting out dustbins:

“Quite often I've said to (clients) 'Do you want me to do so and so?' and they'll say 'Oh no, so and so's not in your job'... [but] if I've asked I don't mind doing it, if it's a little something." Izabelle (domiciliary carer)

Furthermore, the performance of health care tasks does not always follow the formal labour process. For instance, for clients for whom support with their medication is not on their care plan and is strictly forbidden, domiciliary carers reveal that they had administered medication to these clients when they cannot manage by themselves. This is because of the responsibility felt by the domiciliary carers as Nicola alluded to "Could you see somebody without their eye creams?". To acknowledge the range of necessary labours the domiciliaries mention above would then increase care-plan time and, thus, costs (Steinberg, 1999).

Nevertheless, the care plan, in its mechanised approach, also offers some domiciliary carers the opportunity to maintain distance and the person becomes a product to be transformed in the quickest possible time; sometimes without all tasks being completed. After all, as Maria (domiciliary carer) demonstrates, there is an effort bargain involved in caring labour, and a minority of her colleagues resist the pressures to exceed their efforts:

'A poor (domiciliary carer) would leave... 'oh ...I've gotta be at my next visit,...oh I haven't time to wash up' 
This demonstrates the difficulties in relying on work to be performed as part of the informal labour process. In effect, what has been squeezed out of the formal care labour process due to market and control mechanisms is care. Analytically this is a useful separation in order to highlight its taken-for-granted nature, but in practice it can rarely be separated and domiciliary carers' efforts far exceed those formally captured by the employer.

\section{Discussion and conclusion}

Utilising LPT, the analysis presented here emphasises domiciliary care as hard and productive work in order that its value - as a labour process and as a social relationship - may be better recognised and valued. The emphasis on a political economy of care work and the delineation of the formal and informal labour process frames the data collected from those involved in the delivery of domiciliary care, and demonstrates its commodification. Organisational mechanisms, such as rotas and care plans, serve to determine the labour process of domiciliary care work; with the rota defining time parameters and intensifying the work, and care plans offering a clear control agenda via a task-based approach to care. However, the care plan presents only a partial and overly simplistic view of the work involved. Using the boundaries of the labour process as an analytical device the data is structured in such a way that it is possible to examine the labour actually involved in the delivery of care and highlight that only a portion of it is formally recognised. Thus, as the political economy of domiciliary care changes within the context of a financialised capitalism, more activities that used to be in the formal labour process are now squeezed out, such as time to talk to clients or cleaning tasks, and new activities such as health care tasks are squeezed in, and consequently the labour process is intensified. Counter intuitively to the popular belief that care work is unskilled work, and the general de-skilling thesis in work, the introduction of more demanding tasks and clients with higher needs demonstrates domiciliary carers require increasing levels of skill, although this is not recognised or rewarded. Structurally, care-work is heavily influenced by its position in a changing societal and political context where domiciliary carers are firmly placed within a health-care division of labour. The declassifying of tasks from the formal labour process demonstrates how the details of the job are strongly shaped to reduce costs, thus displaying how an economic imperative shapes care-work (Thompson, 1989).

Nevertheless, many domiciliary carers remain engaged in caring activities that used to be recognised as part of their work, but they are only able to do this by giving more of themselves, such as working extra unpaid hours. In LPT terms there is an increased effort 
bargain, as domiciliary carers exceed contractual and moral obligations ensuring the maintenance of an 'ethic of care' (Brown and Korczynski, 2010; Held, 2006). When these off-plan tasks are the result of unwritten managerial expectations they can also be seen as a method of intensifying domiciliary carers' work. Of course, it would be a mistake to separate the physical and emotional elements of caring labour and to insist on analytical boundaries when portraying the day-to-day life of a domiciliary carer. The political economy and the formal and informal labour process are integral to each other. The rich representation of domiciliary care work presented in this paper, framed within LPT, highlights how the labour process is used to shape labour power into a commodity form. However, what the voices of the domiciliary carers reveal is that it is also a social relationship with all of its connectivity and unpredictability. This is never more apparent than when the commodity to be exchanged is a capacity to care for others.

The marketization of care has led to the perception of care work as a 'cost' that must be reduced in order for care providers to remain competitive. Staff terms and conditions diminish, as job insecurity and intensity increase. Whilst government policy espouses improving the care sector through more supportive contracts to care providers, which would enable better employment conditions, allegedly this support has not materialised and instead providers are facing further funding cuts without a corresponding decrease in service expectations (Cunningham and James, 2009). Insights into the day-to-day working lives of domiciliary carers presented here are supported by LPT which usefully draws attention to the material realities of contemporary care-work when downward economic and political pressures strip out the care from caring labour.

\footnotetext{
${ }^{\mathrm{i}}$ The private care sector includes a myriad profit and non-profit organisations

ii An excretory orifice in the stomach.

iii Feeding clients through a tube in their stomach
} 


\section{References}

Ackroyd S and Thompson C (1999) Organisational Misbehaviour. London: Sage.

Aronson J and Neysmith S (2006) Obscuring the costs of home care: restructuring at work. Work, Employment and Society, 20 (1): 27-45.

Baumol W (1993) Health care, education and the cost disease: A looming crisis for public choice. Public Choice 77(1): 17-29.

Bittman M, Matheson G and Meagher G (1999) 'The changing boundary between home and market: Australian trends in outsourcing domestic labour', Work, Employment and Society, (13)2: 249-273

Bolton S (2005b) Women's Work, Dirty Work, Gender, Work and Organisation, 16(2):169186.

Bolton, S. (2010) 'Old Ambiguities, New Developments: Exploring the Emotional Labour Process, in Thompson, P. and Smith, C. (eds.) Working Life, London: Palgrave. pp. 205-222

Bolton S (2005) Emotion Management in the Workplace. London: Palgrave

Brown K and Korczynski M (2010) When Caring and Surveillance Technology Meet: Organizational Commitment and Discretionary Effort in Home Care Work. Work and Occupations 37: 404-432.

Buebeck D (2002) 'Justice and the Labour of Care' in Kittay, E. and Feder, E. (eds.) The Subject of Care: Feminist Perspectives on Dependency. Lanham: Rowman \&Littlefield Publishers, Inc.

Carey M (2006) Everything Must Go? The Privatisation of State Social Work. British Journal of Social Work 38 (5): 918-935.

Carter B and Stevenson H (2012) Teachers, workforce remodelling and the challenge to labour process analysis. Work Employment \& Society, 26 (3):481-496

Cunningham I and James P (2009) The outsourcing of social care in Britain: what does it mean for the voluntary sector workers? Work, Employment and Society, 23 (2): 363-375.

Cohen R (2011) Time, space and touch at work: body work and labour process (re) organisation. Sociology of Health and Illness 33 (2): 189-205.

Cooper J (2004) Analysis of the information needs and flows in the delivery of homecare to older people: an ethnographic study. thesis, University of Wales, Aberystwyth.

Cuban S (2013) Deskilling Migrant Women in the Global Care Industry. Palgrave Macmillan, Basingstoke. 
Davies B and Drake P (2007) Strategies for achieving best value in commissioned home care. International Journal of Public Sector Management 20(3): 206 - 225.

Diamond T (1992) Making Gray Gold. Chicago: University of Chicago Press.

Edwards P (2010) Developing Labour Process Analysis. In: Thompson P and Smith C (eds)

Working Life. London: Palgrave, 29-46.

Ehrenreich B and Hochschild A (2002) Global Woman, London: Grata.

Lee-Treweek G (1997) Women, Resistance and Care: An Ethnographic Study of Nursing Auxiliary Work. Work, Employment and Society 11(1): 47-63.

Lopez S (2006) Emotional Labour and Organised Emotional Care. Work and Occupations 33 (2): 133-60.

McClimont B and Grove K (2004) Who Cares Now? An Updated Profile of Independent Sector Home Care Providers and their Workforce in England, United Kingdom Home Care Association Limited. Available http://www.ukhca.co.uk/pdfs/whocaresnow.pdf

McDonald S (2005) Studying actions in context: a qualitative shadowing method for organizational research. Qualitative Research 5(4): 455-473.

Milligan C and Wiles J (2010) Landscapes of care. Progress in Human Geography 34(6): 736-754.

Nare L (2011) The Moral Economy of Domestic and Care Labour. Sociology 45(3): 396-412.

Rubery J and Urwin P (2011) Bringing the employer back in: why social care needs a standard employment relationship. Human Resource Management Journal 21: 122 137.

Sayer A (2007) Moral economy and employment. In: Bolton SC and Houlihan M (eds) Searching For The Human In Human Resource Management: Theory, Practice, And Workplace Contexts, London: Palgrave.

Sinclair I, Gibbs I, and Hicks L (2000) The Management and Effectiveness of the Home Care Services. Social Work Research and Development Unit: University of York. Available at: Http://www.york.ac.uk/inst/spru/research/summs/homecareservice.html

Stacey C (2011) The caring self: the work experiences of home care aides. Cornell University Press: New York

Steinberg R (1999) Emotional Labour in Job Evaluation. Annals of the American Academy of Political and Social Science 561(1): 449-82. 
Timonen V. and Doyle M. (2007) Worlds apart? Public, private and non-profit sector providers of domiciliary care for older persons in Ireland, Journal of Aging Studies 21: 255-65.

Thompson P (1989) The Nature of Work. Hampshire: Macmillan. $2^{\text {nd }}$ Edition.

Thompson P and Newsome K (2004) Labour Process Theory, Work and the Employment Relation. In Kaufman B (ed) Theoretical Perspectives on Work and the Employment Relation. Industrial Relations Research Assoc: Illinois, 133-162.

Thompson P and Smith C (2009) Labour Power and Labour Process: Contesting the Marginality of the Sociology of Work. Sociology 43(5): 913-930.

Toynbee P (2007) Rethinking Humanity in Care Work - extract from Hardwork: life in lowpay Britain. In: Bolton S and Houlihan M (eds) Searching for the Human in Human Resource Management. London: Palgrave, 219-243.

Twigg J (2000) Carework as a form of bodywork. Ageing and Society 20: 389-411.

Wolkowitz C (2002) 'The Social Relations of Body Work', Work, Employment and Society, 16, 3: 497-510.

Young R (1999) Prospecting for New Jobs to Combat Social Exclusion: The Example of Home-Care Services. European Urban and Regional Studies 6 (2): 99-113. 
AM CALL To offer any assistance John needs with personal care. To make him a cup of tea and his breakfast if not already had any. John likes to sit at the table for all his meals. Make the bed, John likes his sheets and blankets up to the headboard and tucking in very tight at the bottom of the bed. Empty urine bottles and rinse out and leave near his bed. Wash up and leave the kitchen tidy.

LUNCH CALL To prepare a snack type meal and a drink of John's liking. John likes things like scrambled egg on toast, beans on toast etc. for lunch. He likes his meals to be hot when served to him. Ensure the washing up is done and give general assistance with anything that needs doing.

TEA CALL Calls are to prepare a hot meal for John. He likes his meals to be hot when served to him. He also likes vegetables with his main meal. He does sometimes buy 'meals on wheels' and buys from the local supermarket. He will advise on what he wants on the day. Make a drink. Turn the bed half way down for John, ensuring that the bottom sheets and blankets are tightly tucked in and he has enough at the top of the bed to cover him completely when he is in bed. Close the curtains or blinds if John wants them closing. Ensure he is safe and the key is locked in the keysafe when leaving.

OTHER CALLS Monday there is one hour for domestic duties, generally hoovering up and ensuring the kitchen and bathroom are clean and tidy. Assist with laundry and do any ironing needed. Change the bed when John would like it changing. Fridays there is one hour for shopping. John will do a shopping list with domiciliary. He has specifically requested that domiciliary carers do not buy substitute items if the things he wants are not available.

Figure 1: Anonymised example of a Care Plan

Sharon C. Bolton is Professor of Organisational Analysis and School Director of Research at the Management School, Stirling University, UK. Her research interests include the emotional labour process, public sector management, the nursing and teaching labour process, gender and the professions, dignity in and at work, and the human in human resource management. Research is published widely in leading sociology and management journals. In her previous life, Sharon worked as a Senior Administrator in the public and private sectors.

Gemma Wibberley is a Research Associate, in the Institute for Research into Organisations, Work and Employment (iROWE) at the University of Central Lancashire. She has recently been awarded her $\mathrm{PhD}$ from Lancaster University on the labour process of domiciliary carers. Her wider research interests include conflict in the workplace, employment issues and the changing nature of work.

\section{Acknowledgements}

The research for this paper was part of Wibberley's ESRC funded $\mathrm{PhD}$. Thanks are also owed to those in the domiciliary care community for so generously giving their time. We would also like to thank Paul Thompson and the anonymous reviewers for their feedback. 